\title{
Entre a Europa e o Recife, a contribuição argentina para o "Teatro do Nordeste"
}

Luís Augusto da Veiga Pessoa Reis ${ }^{1}$

Resumo

Este artigo oferece um mapeamento inicial da influência de publicações argentinas no processo de modernização do teatro feito no Nordeste do Brasil, especialmente em Pernambuco, entre as décadas de 1940 e 1960. Examinando referências bibliográficas

citadas de modo recorrente por Hermilo Borba Filho, decerto o principal mentor do chamado "Teatro do Nordeste", observa-se como ideias renovadoras advindas da Europa chegaram ao Recife por meios de livros publicados em Buenos Aires, sofrendo assim, naturalmente, interpretações e adaptações.

Palavras-chave: "Teatro do Nordeste"; Argentina; Hermilo Borba Filho

\section{Abstract}

This article offers a preliminary survey on the influence of Argentinian editions in the modernizing process of the theater done in the Northeast of Brazil, especially in Pernambuco, between the 1940s and the 1960s. By examining the bibliographical references recursively cited by Hermilo Borba Filho, certainly the principal architect of the so-called "Teatro do Nordeste" (Theatre of the Northeast), it is observed how renovating ideas originated in Europe reached Recife through books published in Buenos Aires, being, in this way, naturally mediated and adapted.

Keywords: Theatre of the Northeast; Argentina; Hermilo Borba Filho

\footnotetext{
1 Professor do Departamento de Teoria da Arte e Expressão Artística, da Universidade Federal de Pernambuco - UFPE. Possui graduação em Comunicação Social-Jornalismo (UFPE -1999), mestrado em Comunicação Social pela (UFPE - 2003), e doutorado em Teoria da Literatura (2008-UFPE), com tese sobre o pensamento teatral de Hermilo Borba Filho.
} 
Entretanto, a literatura brasileira não é parte da literatura hispano-americana: tem independência, caráter e fisionomia inconfundíveis. O Brasil é algo mais que uma nação: é um universo linguístico irredutível ao espanhol.

Octavio Paz

Em setembro de 1948, a expressão "Teatro do Nordeste" é criada por Paschoal Carlos Magno, a fim de nomear a produção de jovens autores que, a partir do Recife, inspirados pela atuação de Hermilo Borba Filho à frente do Teatro do Estudante de Pernambuco (TEP), procuravam renovar a criação teatral no país, realizando um dos esforços pioneiros para levar aos palcos, em bases modernas, o universo da cultura nacional; nesse caso, especificamente, o universo da expressão popular nordestina, com os temas de seu romanceiro, as manifestações de sua religiosidade, e a vibração ritualística de suas brincadeiras dramáticas, como o bumbameu-boi, o mamulengo e o pastoril. Ecoavam, portanto, com maior ou menor grau de consciência, ideais do Regionalismo preconizado por Gilberto Freyre desde meados dos anos de 1920.

Décadas depois, o movimento renovador que Paschoal Carlos Magno, do Rio de Janeiro, chamou de "Teatro do Nordeste" receberá, em São Paulo, outra denominação: "Escola do Recife". É sob tal rubrica que, em seu livro Teatro Brasileiro Moderno, Décio de Almeida Prado reúne "um tanto abusivamente" diversos dramaturgos nordestinos - agora não somente os criadores diretamente ligados ao TEP, mas nomes que, na trilha aberta por Hermilo Borba Filho, obtiveram reconhecimento em outras regiões do país, em especial no Rio de Janeiro e em São Paulo. Além do próprio Hermilo e de Ariano Suassuna, o artista mais destacado nessa linhagem, Décio de Almeida Prado menciona José Carlos Cavalcanti Borges, Aristóteles Soares, Osman Lins, Aldomar Conrado, Luiz Marinho, Joaquim Cardozo, Francisco Pereira da Silva, e também o poeta João
Cabral de Melo Neto, pelo seu "auto de Natal pernambucano" Morte e vida severina (Prado, 1996 [1988], p. 84).

Sendo um rótulo, a designação "Teatro do Nordeste" - ou "Escola do Recife" - reconhece e, ao mesmo tempo, discrimina; concede espaço para algo apreciado por ser diferente dos modelos hegemônicos, enquanto impõe, contraditoriamente, uma espécie de domesticação das diferenças, logo procurando circunscrevê-las em uma série de traços previamente reconhecíveis. Como todo rótulo, resulta de complexas negociações de poder entre quem rotula e quem é rotulado, podendo ser percebido, dependendo da perspectiva, ora como instrumento de contenção, ora como estratégia de inserção - ambiguidade particularmente presente nas culturas coloniais, das quais se constitui quase como um traço definidor.

Se de certa forma a modernidade pode ser caracterizada pela cogente idealização de um novo (e decerto inalcançável) tempo-espaço, o teatro feito por Hermilo e por seus companheiros, de franca aspiração modernizante, precisava se reconhecer a partir das novas estéticas teatrais que se anunciavam, de fora para dentro, em dupla presunção de superioridade: primeiramente, a hegemonia da Europa, berço das inovações que desde as últimas décadas do século XIX vinham reformando os palcos mundiais; e, em seguida, quase simultaneamente, a supremacia dos centros mais desenvolvidos do teatro no Brasil, o Rio de Janeiro e São Paulo, onde a sensibilidade artística da nova cena europeia deveria, de modo natural, ser primeiramente compreendida e interpretada.

Todavia, um exame mais atento das bases intelectuais que possibilitaram a construção desse "Teatro do Nordeste" é capaz de revelar um desenho talvez um tanto inesperado no fluxo de informações que alimentaram o projeto artístico-intelectual de Hermilo Borba Filho: constatase que, em grande medida, as novidades da cena europeia, não somente no campo da teoria teatral mas também na própria 
literatura dramática, chegaram ao Recife processadas pelo pensamento teatral argentino, por meio de uma grande quantidade de livros publicados em Buenos Aires.

Assim, nos limites deste artigo, propõe-se uma breve observação dessa complexa e até certo ponto inaudita mediação argentina, entre a modernidade teatral da Europa e a dramaturgia nordestina surgida a partir de meados do século $X X$. Esboça-se, portanto, nestas páginas, uma primeira tentativa de mapeamento da influência exercida pela modernização do teatro em Buenos Aires sobre a modernização do teatro no Recife, um caso de estratégica contaminação entre dois distintos e instigantes centros culturais periféricos, unidos por suas ambições cosmopolitas.

\section{Na estante de Hermilo}

Embora Hermilo Borba Filho também lesse em inglês e em francês, na sua biblioteca pessoal, parcialmente preservada até hoje, a estante de livros estrangeiros é formada majoritariamente por publicações em língua espanhola, grande parte editada em Buenos Aires. Nesse rol, encontram-se não somente traduções de obras escritas por dramaturgos e por teóricos europeus, mas também diversos estudos originalmente produzidos por pensadores do moderno teatro argentino - além de algumas peças de autores portenhos.

Um expressivo indício da relevância dessas edições argentinas na conformação do pensamento teatral de Hermilo é a vasta lista de referências bibliográficas por ele apresentada em seu livro História do teatro, escrito em 1950. Dos 519 itens relacionados, 174 são obras produzidas em Buenos Aires (33,5\%). Em 1968, quando esse volume é relançando, ampliado e revisado, com o título de História do espetáculo, a presença de livros argentinos na bibliografia permanece significativa: 45, entre as 215 obras listadas (21\%). Agora, por um lado, a indústria editorial brasileira se encontrava mais desenvolvida, possibilitando uma presença maior de títulos nacionais; por outro, nota-se um aumento na indicação de obras em inglês e em francês, talvez importadas com mais facilidade.

No entanto, como se sabe, estatísticas e porcentagens, por si só, não são os melhores mecanismos de aferição quando se trata de assuntos artísticos e intelectuais. $\mathrm{O}$ que realmente importa, nesse intento, não é a quantidade de referências, mas sim a percepção de como certas ideias e informações presentes em obras argentinas repercutiram na produção criativa de Hermilo Borba Filho, como artista e como teórico.

\section{Empréstimos de ideias, construções de ideais}

Certa vez, em 1951, após enfrentar ferrenhas críticas à sua tragédia $O$ vento do mundo, rechaçada por setores mais conservadores da imprensa recifense, Hermilo, sem esconder certa dose de pedantismo, relaciona, em matéria publicada na revista Nordeste, uma lista de livros internacionais que, segundo ele, precisavam urgentemente ser lidos pelos "estudiosos do teatro na Província”. Entre os autores indicados, é dado importante destaque a Alfredo de La Guardia e José Maria Monner Sans.

Com referência às obras de crítica, podemos citar como as melhores: Panorama del novo teatro [1942], de José Maria Monner Sans, autor argentino dos mais eruditos na arte dramática, a quem devemos, também, uma excelente interpretação de Pirandello. O livro de Monner Sans põe o leitor em contato com as várias tendências do teatro moderno, os estilos, as influências, estudando, separadamente, personalidades como Lenormand, Shaw, O’Neill, Kaiser e Benavente. Ainda outro argentino ${ }^{2}$ se faz notar no campo da crítica dramática, Alfredo de La Guardia, com seu livro El teatro contemporâneo [1947], cujo primeiro volume atinge

2 Na verdade, La Guardia era nascido na Espanha, embora tenha migrado para a Argentina ainda muito jovem e se naturalizado argentino. 
o teatro realista, ocupando-se o segundo do simbolismo até as tendências mais atuais. Escrito com grande agudeza crítica, o livro de Alfredo de La Guardia situa a dramática de vários autores nos seus justos limites, estendendo-se a respeito de Ibsen e Shaw, para ele dramaturgos-marcos na história da literatura dramática. (Borba Filho in Nordeste, 1951).

Não era a primeira vez em que Hermilo Borba Filho expunha sua admiração por esses dois teóricos. Eles já eram, ao lado de outros autores argentinos ou radicados na Argentina, como a russa Galina Tolmacheva, nomes conhecidos pelos leitores das colunas teatrais que escrevia para jornais recifenses desde os primeiros anos da década de 1940.

No dia 3 de setembro de 1944, por exemplo, ao se pronunciar pela primeira vez sobre a peça Vestido de noiva, de Nelson Rodrigues, marco inconteste da renovação teatral brasileira, Hermilo menciona tanto Alfredo de La Guardia quanto José Maria Monner Sans, buscando nesses autores estrangeiros, ao lado de nomes como os da escritora inglesa Virginia Woolf, do dramaturgo francês Jean Jacques Bernard e do teórico russo Nicolas Evreinoff, respaldo para a sua argumentação, sublinhando a importância e a modernidade do texto de Nelson. Enquanto Monner Sans aparece apenas como fonte de uma declaração feita por Jean Jacques Bernard, Alfredo de La Guardia é citado textualmente, em espanhol, reforçando a ideia, apresentada então por Hermilo, de que Nelson Rodrigues, em Vestido de noiva, havia criado uma verdadeira tragédia moderna.

La densidad de la linea y la complejidad del análisis psicológico son los elementos que renuevam, otra vez, la tragedia. A la lucha de semidieoses, titanes e héroes, a la fluctuación del hombre en sus característicos, sucede el abismamiento del ser humano en médio del debate de las insospechadas fuerzas hondo mundo subliminal (Apud Borba Filho in Jornal do Commercio, 3/9/1944).
Não por acaso, é essa compreensão de tragédia moderna, em que pulsões inconscientes se encarregam de substituir os castigos e os caprichos dos deuses na definição dos destinos humanos, que se vislumbra nas peças escritas por Hermilo ao final da década de 1940, nomeadamente: Electra no circo, João sem terra, A barca de ouro, além da já citada $O$ vento do mundo. Nesse viés, é oportuno lembrar que, apesar de ter se consagrado nacionalmente sobretudo por meio de suas comédias, especialmente depois do retumbante sucesso do Auto da Compadecida, de Ariano Suassuna, em 1957, a moderna dramaturgia nordestina, inicialmente, estava voltada, com muita determinação, para a produção de tragédias, decerto como forma de se distinguir das revistas e das comédias de costumes, ambas de inequívoco interesse comercial, consideradas, então, empecilhos ao aprimoramento da arte dramática no país. $\mathrm{O}$ próprio Ariano estreia como autor teatral, sob nítida influência das peças de Federico García Lorca, vencendo o concurso de dramaturgia promovido pelo Teatro de Estudante de Pernambuco, em 1947, com a tragédia Uma mulher vestida de sol.

\section{Regionalismos e deslocamentos}

Federico García Lorca, por sua vez, decerto a inspiração mais perceptível na dramaturgia produzida a partir do TEP, parecia comprovar, no teatro, a viabilidade da equação proposta pelo Regionalismo de Gilberto Freyre - o "espírito da época" entre aqueles jovens intelectuais do Recife - levando ao palco, com muita força poética o trinômio, tradição, região e modernidade. Pois bem, é importante notar que o autor de Bodas de sangre foi apresentado a Hermilo por meio do estudo García Lorca - persona Y creación, de Alfredo de La Guardia, publicado em 1941. Em seus escritos, em diferentes momentos de sua intensa carreira teatral, Hermilo reconhecerá La Guardia como uma de suas primeiras e mais importantes referências sobre o universo poético de Lorca. Em agosto de 1948, 
na série de cinco longos artigos intitulada Lorca - tentativa de compreensão, publicada no Suplemento Literário da Folha da Manhã, Hermilo cita La Guardia em quatro ocasiões, transcrevendo trechos de seu livro sobre o poeta andaluz, obra apresentada como "a melhor biografia e o melhor estudo crítico a respeito de García Lorca" (Borba Filho in Folha da Manhã, 1/8/1948).

Mas as afinidades entre La Guardia e Hermilo Borba Filho não param por aí. Os dois, como agentes culturais situados longe da Europa, à margem do grande centro da modernidade teatral, procuraram, ao alcance de suas possibilidades, inserir a cena sul-americana nas historiografias da arte dramática ocidental. No manual História do teatro, Hermilo inclui um capítulo sobre o teatro argentino e outro sobre o teatro brasileiro. Já em El teatro contemporâneo, de La Guardia, que trata sobretudo do teatro europeu após o advento da literatura realista, há espaço, embora desigual, não apenas para o teatro feito na Argentina, tratado naturalmente com mais amplitude, mas também, para o teatro do México, o do Uruguai e, em bem menor consideração, o teatro de "otros países iberoamericanos", no caso, Chile, Brasil e Peru. No prefácio, escrito em 1945, o autor expressa, com bom humor, sua indignação em relação ao desconhecimento da arte teatral latino-americana por parte dos historiadores do teatro ocidental:

En una minuciosa History, de reciente data, sólo se cita a Pedro Echagüe y Martiniano Leguizamón como autores argentinos, y poucas líneas más abajo se dice: 'Raúl Roulien is the principal actor of Brazil', agregándose, en seguida, como única actriz a Carmen Miranda (La Guardia, 1952, p. 8-9).

Sobretudo Alfredo de La Guardia, mas também José Maria Monner Sans, além da russa-argentina Galina Tolmacheva, com seu seminal estudo Creadores del teatro moderno, publicado em Buenos Aires em 1942, acompanharão toda a trajetória artístico- intelectual de Hermilo, através de décadas, como fontes valiosas para a elaboração de suas próprias ideias.

\section{A Rússia e a França em Buenos Aires}

O que La Guardia representou, para Hermilo, em relação a Lorca, Tolmacheva, ela própria uma ex-aluna de Stanislavski e ex-mulher de Komisarjevsky (Solari, 2012), representou em relação aos encenadores russos do início de século XX e, também, em relação ao francês Jacques Copeau, outra importante baliza na evolução do pensamento estético do teatrólogo pernambucano.

Quando, em novembro de 1949, em sua coluna na Folha da Manhã, Hermilo anuncia a morte de Copeau, é a visão de Tolmacheva sobre o encenador francês que ele invoca: "Uma luta de morte travou-se entre Paris e Copeau: Paris insistia no mau gosto em matéria teatral, continuava apreciando tão somente o espetáculo frívolo, procurando no palco somente um passatempo; Copeau não se curvava, proclamando com sua obra o sagrado da arte cênica" (apud Borba Filho in Folha da Manhã, 12/11/1949). Anos depois, em seu ensaio Diálogo do encenador, escrito em 1964, Hermilo segue repercutindo as impressões de Galina Tolmacheva sobre Jacques Copeau, ressaltando a missão, quase "religiosa", desse moderno criador da cena francesa, "um dos espíritos mais nobres e puros que já apareceram no mundo do teatro" (Borba Filho 2005 [1964], p.106), na tentativa de dar dignidade artística a uma atividade então valorizada sobretudo como entretenimento. Algumas páginas adiante, quando Hermilo trata da escola russa de encenação, as citações ao livro de Tolmacheva ganham ainda mais relevo. Referindo-se a Meyerhold, Hermilo escreve: "Lembro-me do que disse Galina Tolmacheva: 'Balagnchik, peça simbolista de Alexandre Blok, com seu ambiente propício, serviu-lhe para demonstrar a maneira de poder 'teatralizar o teatro', ao qual julgava perdido pelo naturalismo'" (apud Borba Filho, 2005 [1964], p. 124).

Ora, entre tantas outras questões, es- 
tas particulares duas demandas, pelo reconhecimento da dignidade artística da arte dramática e pela necessidade de se "teatralizar" o teatro, serão temas recorrentes em toda a vida criativa de Hermilo, deixando marcas definidoras em grande parte da moderna dramaturgia nordestina. Não são, evidentemente, ideias exclusivas de Galina Tolmacheva, como também não pertencia apenas a La Guardia a definição de tragédia moderna apresentada há pouco, nem a rigor esses entendimentos dependeram essencialmente do ambiente teatral argentino para se desenvolver; mas o fato é que chegaram a Hermilo e, por meio dele ao teatro recifense, filtrados pela indústria editorial portenha, com suas prioridades e com suas necessidades, e isso precisa ser levado em conta quando se busca um entendimento ampliado da modernização do teatro brasileiro.

\section{De costas para a plateia, como no teatro moderno}

Para além do campo estrito dos estudos teatrais, a percepção dessa silenciosa participação argentina em um movimento artístico nordestino talvez possa denunciar que as trocas entre culturas periféricas, colonizadas, são muito mais complexas e difusas do que geralmente se supõe. Em certa medida, o reconhecimento de que, embora decerto inopinadamente, ideias e valores teatrais argentinos, em suas respostas a estímulos europeus, puderam de alguma maneira interferir nos rumos da moderna dramaturgia produzida no Nordeste brasileiro parece, por exemplo, ser um dado capaz de interpelar a imagem, irremediavelmente estática, e ainda muitas vezes evocada, de um "Brasil de costas para a América Latina". O que se vê, nesse episódio da modernização do teatro nordestino, é um canal fluente, espontâneo, conectando dois polos culturais sul-americanos, ambos aparentemente "de costas para a América Latina"; ambos igualmente atentos aos sinais emitidos pela moderna cena teatral europeia, intuindo ou não que tais informações, em última instância, contribuiriam para o au- toconhecimento, para o aperfeiçoamento e para a valorização das potencialidades expressivas de suas próprias culturas, de seus próprios teatros. Afinal, talvez não seja incorreto pensar que, sem o conhecimento do moderno teatro europeu, e sem o conhecimento de como o moderno teatro europeu era interpretado em outras culturas periféricas, como a argentina, talvez Hermilo e seu grupo tivessem levado muito mais tempo para perceber, por exemplo, a beleza e a modernidade cênica existentes nos espetáculos populares do Nordeste, como o bumba-meu-boi, o pastoril e o mamulengo, operação que originou uma matriz estética que, na atualidade, é cada vez mais estudada, dentro e fora do Brasil, por diversos setores dos estudos teatrais, não apenas no campo da literatura dramática, mas especialmente no que tange à arte encenação e à formação do intérprete teatral. 


\section{REFERÊNCIAS}

BORBA FILHO, Hermilo. Diálogo do encenador - Teatro do povo, Mise-en-scène e A donzela Joana. Prefácios Luís Augusto Reis; Carlos Reis; Leda Alves. Recife: Edições Bagaço e Editora Massangana, 2005.

. História do espetáculo. Rio de Janeiro: Edições Cruzeiro, 1968.

dante do Brasil, 1950.

. História do teatro. Rio de Janeiro: Livraria-Editora da Casa do Estu-

CARVALHEIRA, Luiz Maurício. Por um teatro do povo e da terra: Hermilo Borba Filho e o Teatro do Estudante de Pernambuco. Prefácio de Maximiniano Campos. Recife: Fundarpe, 1986.

LA GUARDIA, Alfredo. El teatro contemporâneo. Buenos Aires: Editorial Schapire, 1947. . García Lorca - persona y creación. Buenos Aires: Sur, 1941.

PAZ, Octavio. Convergências: ensaios sobre arte e literatura. Rio de Janeiro: Rocco, 1991.

PRADO, Décio de Almeida. O teatro brasileiro moderno. São Paulo: Perspectiva, 1996 (1988).

REIS, Luís Augusto. Fora de cena, no palco da modernidade: um estudo do pensamento teatral de Hermilo Borba Filho. Prefácio de Tania Brandão. Recife: Editora da UFPE, 2009.

SANS, José Maria Monner. Panorama del novo teatro. Buenos Aires: Editorial Lousada S. A., 1942.

SOLARI, Carla. Stanislavsky en la obra del director, maestro y actor Miguel Guerberof. Buenos Aires: Editorial Argus- $a, 2012$.

TOLMACHEVA, Galina. Creadores del teatro moderno. Buenos Aires: Editorial Centurión, 1946. 